\title{
TWO-DIMEN SION AL MATHEMATICAL MODEL FOR CARBON MONOXIDE OXIDATION PROCESS ON THE PLATINUM CATALYST SURFACE
}

\author{
Petro Kostrobii ${ }^{1}{ }^{*}$, Iryna Ryzha ${ }^{1}$
}

https://doi.org/10.23939/chcht12.04.451

\begin{abstract}
The two-dimensional mathematical model for carbon monoxide $(\mathrm{CO})$ oxidation on the platinum $(\mathrm{Pt})$ catalyst surface is investigated according to the LangmuirHinshelwood (LH) mechanism. The effects of structural changes of the catalytic surface and the substrate temperature are taken into account. It is shown that when twodimensionality and structural changes are accounted for, both the dynamics of oxidation process and the stability region change.
\end{abstract}

Keywords: reaction of catalytic oxidation, reactiondiffusion model, mathematical modeling of reactiondiffusion processes.

\section{Introduction}

One of the mechanisms of catalytic carbon monoxide oxidation on platinum is the classical LangmuirHinshelwood (LH) mechanism [1]. In the LH mechanism the two reacting species $\mathrm{CO}$ and oxygen have to adsorb on the catalytic surface before the reaction takes place:

$$
\begin{aligned}
\mathrm{O}_{2}+2^{*} & \rightarrow 2 \mathrm{O}_{a d s} \\
\mathrm{CO}+* & \leftrightarrow \mathrm{CO}_{a d s} \\
\mathrm{CO}_{a d s}+\mathrm{O}_{a d s} & \rightarrow \mathrm{CO}_{2}+2^{*}
\end{aligned}
$$

where "*” denotes an empty adsorption site on the catalytic surface and the subscript "ads" denotes an adsorbed state of respective species.

Oxygen desorption is neglected because it is very unlikely to occur in the range of temperatures at which experiments are conducted [2]. Since diffusion coefficient of adsorbed oxygen is 3-4 orders of magnitude smaller than $\mathrm{CO}$ diffusion coefficient [3], adsorbed oxygen is considered to be immobile.

The processes of surface reconstruction of the catalyst atoms play a crucial role in heterogeneous catalysis. The clean $\operatorname{Pt}(110)$ surface has a $(1 \times 2)$ structure [4]. During the reaction oxygen and carbon monoxide

\footnotetext{
${ }^{1}$ Lviv Polytechnic National University

12, S. Bandera St., 79013 Lviv, Ukraine

*ira.saj@gmail.com

(C) Kostrobii P., Ryzha I., 2019
}

adsorb on the Pt surface. If $\mathrm{CO}$ coverage exceeds specific critical value the surface reconstructs into $(1 \times 1)$ bulk structure [5]. When oxygen and $\mathrm{CO}$ react, carbon dioxide is formed, and the surface returns to its initial configuration. Such structural changes influence the rates of other elementary oxidation processes, therefore, it should be taken into account when developing a mathematical model of reaction.

For the temperature $\sim 500 \mathrm{~K}$ further structural changes of the $\mathrm{Pt}(110)$ surface are observed for ongoing reaction, namely, the formation of new crystal planes (faceting) [6]. It substantially changes the adsorption properties of the crystal, in particular with respect to oxygen.

For thin plate catalysts the heat generated in the chemical processes may dynamically change the temperature $T$ of the catalyst surface. Even small changes of $T$ may alter the $\mathrm{CO}$ oxidation dynamics dramatically. It is therefore also relevant to analyze the heat balance conditions which make it possible to understand the characteristic time and space scales of the temperature field that may influence the chemical reaction.

In the present paper a new kinetic model for the description of time dynamics of $\mathrm{CO}$ oxidation on $\mathrm{Pt}(110)$ surface is developed. The effect of two-dimensionality, faceting and temperature on the dynamics of the reaction is investigated.

\section{Theory}

We consider a model for catalytic $\mathrm{CO}$ oxidation that accounts for diffusion of molecules of $\mathrm{CO}$ on $\mathrm{Pt}(110)$ surface. Unlike existing models [6, 7], the catalytic surface is assumed to be flat with a given Cartesian coordinate system XOY. The time evolution of $\mathrm{CO}(u)$ and $\mathrm{O}(v)$ surface coverages are determined by the following kinetic equations [8]:

$$
\begin{gathered}
\frac{\partial u}{\partial t}=p_{u} \kappa_{u} s_{u}\left(1-\left(u / u_{\text {sat }}\right)^{q}\right)-k_{\text {des }} u-k_{r} u v+ \\
644^{i \text { itgsion }} 488 \\
+D_{x} \frac{\partial^{2} u}{\partial x^{2}}+D_{y} \frac{\partial^{2} u}{\partial y^{2}}
\end{gathered}
$$




$$
\begin{gathered}
\frac{\partial v}{\partial t}=p_{v} \kappa_{v} s_{v}\left(1-u / 4_{s a t}-v / v_{s a t}\right)^{2}-k_{r} u v
\end{gathered}
$$

where $p_{u}$ and $p_{v}$ are the partial pressures of respective species; $\kappa_{u}$ and $\kappa_{v}$ are the impingement rates; $s_{u}$ and $s_{v}$ are the sticking coefficients; $u_{s a t}$ and $v_{s a t}$ refer to the maximum coverages, namely the saturation coverages; $k_{r}$ and $k_{\text {des }}$ are the rates of oxidation reaction and $\mathrm{CO}$ desorption; $D_{x}$ and $D_{y}$ are CO diffusion coefficients in $x$ and $y$ directions, respectively. The factor $q=3$ models the asymmetric inhibition of $\mathrm{CO}$ and $\mathrm{O}_{2}$ adsorption since the adsorbed $\mathrm{CO}$ blocks oxygen adsorption stronger [9].

The structural phase transition $(1 \times 2) \leftrightarrow(1 \times 1)$ on the $\mathrm{Pt}(110)$ surface is modeled by the following equation [10]:

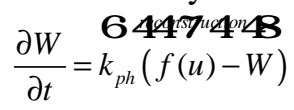

where variable $W$ denotes the fraction of the surface in the non-reconstructed structure (surface of type $(1 \times 1)$ ); $f(u)$ is a non-decreasing smooth function of the interval [0;1]; coefficient $k_{p h}$ is a rate of structural phase transition.

The function $f(u)$ is modeled [7]:

$$
f(u)=\frac{1}{1+\exp \left(\frac{u_{0}-u / u_{\text {sat }}}{\delta u}\right)}
$$

where parameter $u_{0}$ determines the threshold value above which adsorbed $\mathrm{CO}$ molecules significantly influence the structure of the surface and $\delta u$ is the steepness of this threshold.

The oxygen sticking coefficient $s_{v}$ is modified in Eq. (2) and can be rewritten as a linear combination of the values for the $(1 \times 2)$ and $(1 \times 1)$ structures:

$$
s_{v}=s_{v}^{(1)} W+s_{v}^{(2)}(1-W)
$$

where $s_{v}^{(1)}$ and $s_{v}^{(2)}$ are oxygen sticking coefficients in $(1 \times 1)$ and $(1 \times 2)$ phases, respectively.

To complete the model thermal processes generated in chemical reactions should be taken into account. In phenomenological definition [11] the heat balance equation includes the catalyst surface thermal conduction and the heat of oxidation reaction:

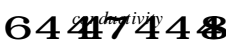

$$
\begin{aligned}
& c_{p} \rho \frac{\partial T}{\partial t}=\kappa_{\text {cond }}\left(\frac{\partial^{2} T}{\partial x^{2}}+\frac{\partial^{2} T}{\partial y^{2}}\right)- \\
& 64444 \text { कीator } 4 \text { ion } 4448 \\
& -2 n_{\text {sites }} \Delta H_{u, a d s} p_{u} \kappa_{u} s_{u}\left(1-\left(u / u_{\text {sat }}\right)^{3}\right)- \\
& 64444444 \text { propin } 4444448 \\
& -2 n_{\text {sites }} \Delta H_{v, a d s} p_{v} \kappa_{v} s_{v}\left(1-u / u_{\text {sat }}-v / v_{\text {sat }}\right)^{2}-
\end{aligned}
$$

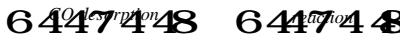

$$
\begin{aligned}
& -2 n_{\text {sites }} \Delta H_{\text {des }} k_{\text {des }} u-2 n_{\text {sites }} \Delta H_{r} k_{r} u v
\end{aligned}
$$

where $c_{p}$ is the heat capacity, $\rho$ is the density, $\kappa_{\text {cond }}$ is the thermal conductivity of the catalyst; $n_{\text {sites }}$ is the number of active sites in $1 \mathrm{~cm}^{2}$ of $\operatorname{Pt}(110)$ surface [11]; $\Delta H_{u, a d s}$ and $\Delta H_{v, a d s}$ are the heats of adsorption of respective species; $\Delta H_{\text {des }}$ is $\mathrm{CO}$ desorption activation energy; $\Delta H_{r}$ is the enthalpy of oxidation reaction.

The degree of faceting $Z$ is a consequence of a competition between the formation of facets, with the free energy of the reaction as a driving force, and thermal annealing, for which the flat surface is thermodynamically favored. It is modeled by the following equation [6]:

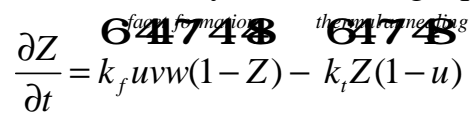

where $k_{f}$ and $k_{t}$ are the rates of facet formation and thermal annealing, respectively.

The oxygen sticking coefficient $s_{v}$ is significantly enhanced on a faceted surface, so (5) is modified:

$$
s_{v}=s_{v}^{(1)} W+s_{v}^{(2)}(1-W)+s_{v}^{(3)} Z
$$

where $s_{v}^{(3)}$ is an increase of $s_{v}$ for maximum faceting $(Z=1)$.

The rates of the reaction, desorption, phase transition and thermal annealing are dependent on temperature $T$ and are determined by the Arrhenius equations [12]:

$$
k=k^{0} \exp (-E / R T)
$$

where $k^{0}$ is the temperature independent coefficient; $E$ is the activation energy; $R$ is the universal gas constant. The effect of the existing near-surface electric field on activation energies was investigated in papers [13, 14]. It was shown there that the effect of near-surface electric fields can be neglected.

Eqs. (1)-(3), (6), (7) compose proposed a twodimensional mathematical model for $\mathrm{CO}$ oxidation process on the platinum catalyst surface.

\section{Results and Discussions}

For numerical analysis Eqs. (1)-(3), (6), (7) are transformed into dimensionless form by substituting:

$$
\begin{aligned}
& u=u_{\text {sat }} U, v=v_{\text {sat }} V, T=T_{0} \Upsilon^{\prime \prime} \text {, } \\
& x=l_{0} \& /, y=l_{0} g /, t=t_{c} q^{k}
\end{aligned}
$$

where

$$
t_{c}=v_{\text {sat }} / p_{u} \kappa_{u} s_{u}
$$

Parameter $l_{0}$ is chosen according to experimental data for the size of Pt-crystal $l_{0} \sim 10^{-3} \mathrm{~cm} \mathrm{[15].}$ $T_{0}=540 \mathrm{~K}$ is the temperature at which the reaction of $\mathrm{CO}$ oxidation has the maximum $\mathrm{CO}_{2}$ output. 
In dimensionless form Eqs. (1)-(3), (6), (7) compose a mathematical model for reaction of $\mathrm{CO}$ oxidation on Pt surface:

$$
\begin{aligned}
& \frac{\partial U}{\partial \%}=\frac{v_{\text {sat }}}{u_{\text {sat }}}\left(1-U^{3}\right)-k_{\text {des }}^{\%} U-k_{r}^{\%} q_{\text {sat }} U V+ \\
& +B_{x}^{\circ}\left(\frac{\partial^{2} U}{\partial \mathscr{Q} \%}+D_{0} \frac{\partial^{2} U}{\partial \%_{0}}\right) \\
& \frac{\partial V}{\partial \%}=\not / s_{v}(1-U-V)^{2}-k_{r}^{\%} q_{s a t} U V \\
& \frac{\partial W}{\partial \%}=k_{p h}^{\%}\left[1+\exp \left(\frac{u_{0}-U}{\delta u}\right)\right]^{-1}-k_{p h}^{\%} W \\
& \frac{\partial \%}{\partial \%}=\kappa_{\text {cond }} \%\left(\frac{\partial^{2} T^{\%}}{\partial \mathscr{Q} \%}+\frac{\partial^{2} T^{2} \%}{\partial \%}\right)- \\
& -\Delta H_{u, a d s}^{\circ} v_{s a t}\left(1-U^{3}\right)- \\
& -\Delta H_{v, a d s}^{\circ} \beta P_{v} s_{v} v_{s a t}(1-U-V)^{2}- \\
& -\Delta H_{\text {des }}^{\circ} \%_{d e s}^{\%} u_{s a t} U-\Delta H_{r}^{\%} k_{r}^{\%} q_{s a t} v_{\text {sat }} U V \\
& \frac{\partial Z}{\partial \%}=k_{f}^{\%} u_{s a t} v_{s a t} U V W(1-Z)- \\
& -k_{t}^{\mathscr{Q}}\left(1-u_{s a t} U\right)
\end{aligned}
$$

where $k_{\text {des }}^{\%}=k_{\text {des }} t_{c}, k_{r}^{\%}=k_{r} t_{c}, k_{p h}^{\%}=k_{p h} t_{c}, k_{f}^{\%}=k_{f} t_{c}$,

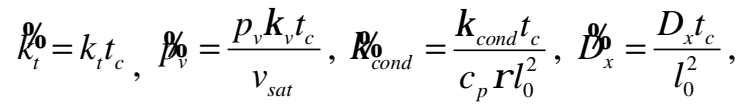

$D_{0}=\frac{D_{y}}{D_{x}}, \Delta H_{u, a d s}^{\%_{s}}=\frac{2 n_{\text {sites }}}{c_{p} \rho T_{0}} \Delta H_{u, a d s}, \Delta H_{v, a d s}^{\circ}=\frac{2 n_{\text {sites }}}{c_{p} \rho T_{0}} \Delta H_{v, a d s}$,

$\Delta H_{\text {des }}^{\circ}=\frac{2 n_{\text {sites }}}{c_{p} \rho T_{0}} \Delta H_{\text {des }}, \Delta H_{r}^{\%}=\frac{2 n_{\text {sites }}}{c_{p} \rho T_{0}} \Delta H_{r}$.

Parameter values used in numerical calculations are given in [8] and Table 1 [6].

The results of numerical analysis of model (13) are presented in Figs. 1 and 2.

Figs. 1-2 show that the dependence dynamics of surface coverages $U(\ell, 09), \%$ \% and $V(\ell, 09 /, \%$ \% and the fraction of the surface in the non-reconstructed structure $(1 \times 1)$

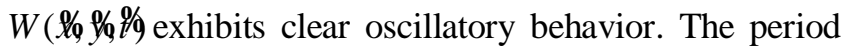
of oscillations has a weak dependence on $y$-coordinate. At the same time the amplitude of oscillations changes with a change of $y$. This shows the effect of $\mathrm{CO}$ diffusion along $O Y$-axis despite the fact that $D_{y} \sim 0,1 D_{x}[3,15]$.

In contrast to the one-dimensional model [16], the dynamics of surface coverages dependency we have calculated demonstrates mixed-mode oscillations (MMO) which were observed experimentally on $\operatorname{Pt}(110)$ [17].

Table 1

Parameters of mathematical model

\begin{tabular}{|l|l|l|}
\hline$k_{f}$ & Rate of facet formation & $k_{f}=0.031 / \mathrm{s}$ \\
\hline$k_{t}$ & Rate of thermal annealing & $k_{t}^{0}=2.65 \cdot 10^{5} 1 / \mathrm{s}$ \\
\cline { 3 - 3 } & & $E_{t}=83.72 \mathrm{~kJ} / \mathrm{mol}$ \\
\hline$s_{v}^{(3)}$ & Increase of $s_{v}$ for maximum faceting $(Z=1)$ & $s_{v}^{(3)}=0.2$ \\
\hline
\end{tabular}

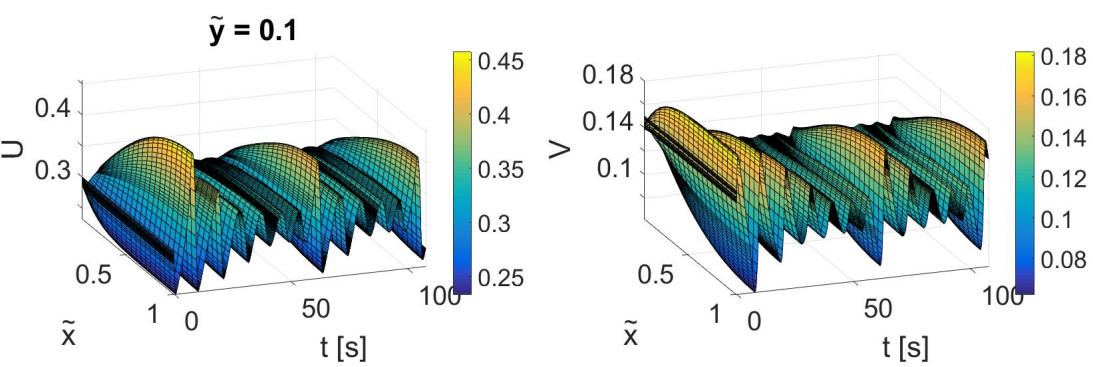

Fig. 1. Dependency of $\mathrm{CO} U(x, y, t)$ and $\mathrm{O} V(x, y, t)$ surface coverages and fraction of the surface in the nonreconstructed structure $(1 \times 1) W(x, y, t)$ and degree of faceting $Z(x, y, t)$ for $D_{x} / D_{y}=10, p_{u}=3.53 \cdot 10^{-3} \mathrm{~Pa}$, $p_{v}=8.53 \cdot 10^{-3} \mathrm{~Pa}$ and certain value of coordinate $y=0.1$

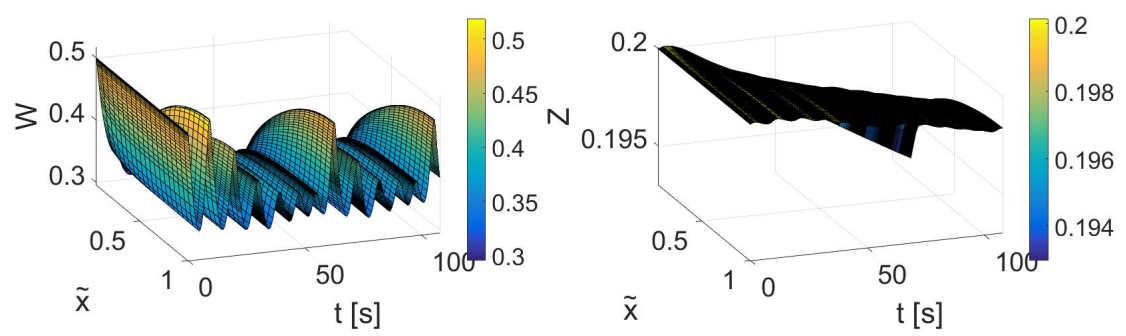



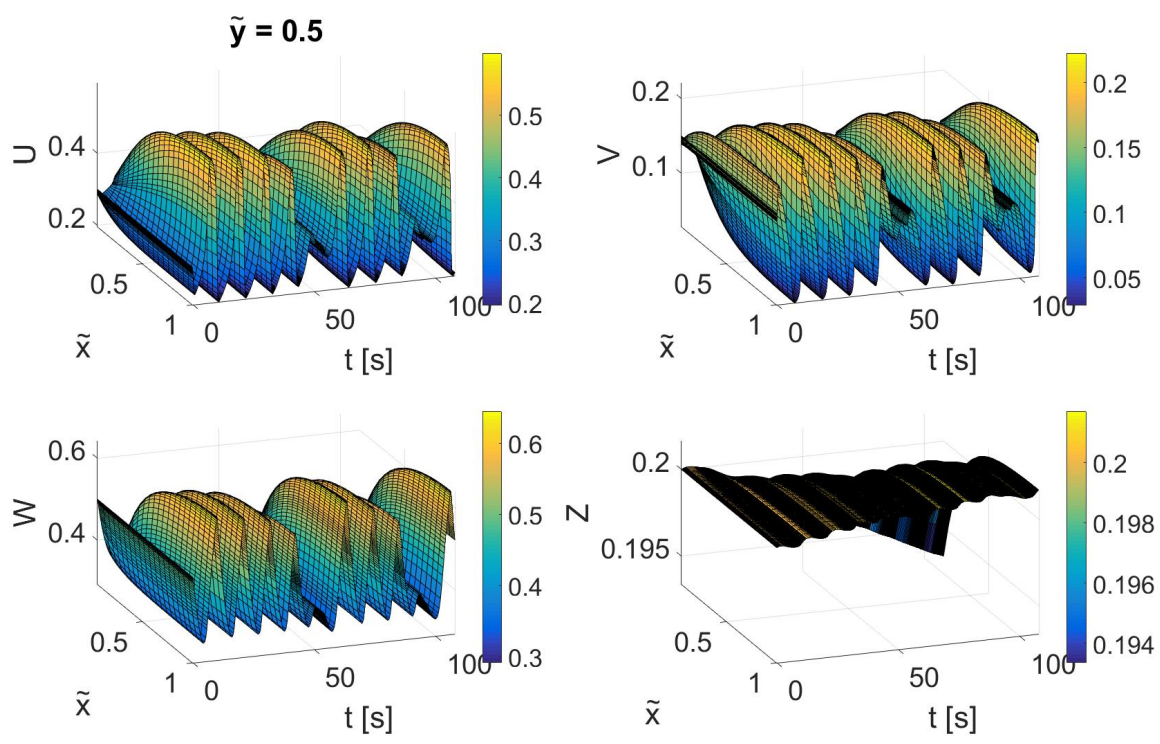

Fig. 2. Dependency of $\mathrm{CO} U(x, y, t)$ and $\mathrm{O} V(x, y, t)$ surface coverages and fraction of the surface

in the non-reconstructed structure $(1 \times 1)$

$W(x, y, t)$ and degree of faceting $Z(x, y, t)$ for $D_{x} / D_{y}=10, p_{u}=3.53 \cdot 10^{-3} \mathrm{~Pa}$, $p_{v}=8.53 \cdot 10^{-3} \mathrm{~Pa}$ and certain value of coordinate $y=0.5$

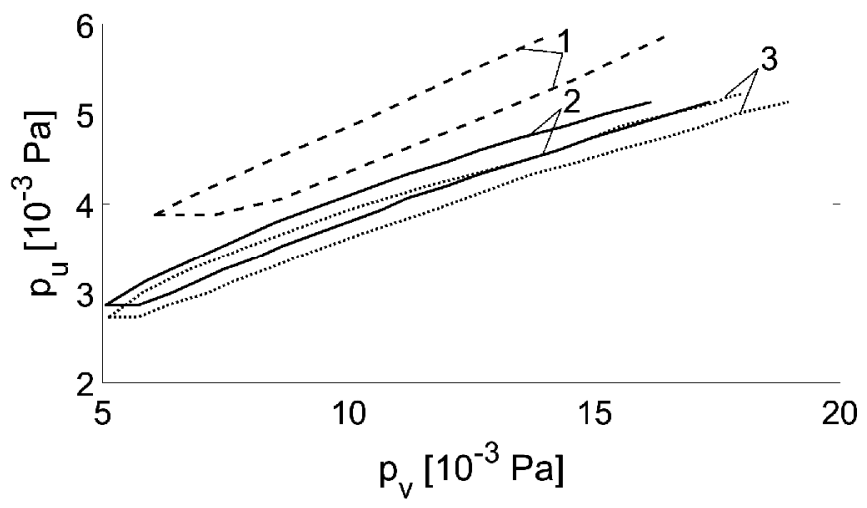

Fig. 3. Stability diagram for reaction of $\mathrm{CO}$ oxidation in the partial pressures $\left(p_{u}, p_{v}\right)$-parameter plane for two-dimensional model (13) (line 2), two-dimensional model without taking faceting into account [8] (line 3) and one-dimensional model [16] (line 1)

The oscillatory character has a strong dependency on the initial values of the partial pressures $p_{u}$ and $p_{v}$. A comparison of stability regions (oscillatory behaviors) for model (13) and one-dimensional model [16] and twodimensional model without taking an equation for faceting into account [8] is depicted in Fig. 3. It can be seen that the stability region for reaction of $\mathrm{CO}$ oxidation on the catalyst surface in two-dimensional case is narrower than the stability region for the one-dimensional model and shifts to the region of small $\mathrm{CO}$ and $\mathrm{O}_{2}$ partial pressures.

\section{Conclusions}

In the present paper the two-dimensional mathematical model for carbon monoxide oxidation according to the Langmuir-Hinshelwood mechanism is developed and investigated. It is shown that when faceting and two-dimensionality of the catalyst surface are accounted for, the stability region of $\mathrm{CO}$ oxidation reaction changes. The reaction of $\mathrm{CO}$ oxidation on Ptcatalyst surface has an oscillating character in the stability region. Moreover mixed mode oscillations are obtained, which could not be predicted by the one-dimensional model [16] when equation for degree of faceting is not accounted for [6].

\section{References}

[1] Baxter R., Hu P.: J. Chem. Phys., 2002, 116, 4379. https://doi.org/10.1063/1.1458938

[2] Wilf M., Dawson P.: Surf. Sci., 1977, 65, 399. https://doi.org/10.1016/0039-6028(77)90456-3

[3] GomerR.: Rep. Prog. Phys., 1990, 53, 917. https://doi.org/10.1088/0034-4885/53/7/002

[4] Kellogg G.: Phys. Rev. Lett., 1985, 55, 2168. https://doi.org/10.1103/PhysRevLett.55.2168 
[5] Gritsch T., Coulman D., Behm R., Ertl G: Phys. Rev. Lett., 1989, 63, 1086. https://doi.org/10.1103/PhysRevLett.63.1086

[6] Krischer K., Eiswirth M., Ertl G.: J. Chem. Phys., 1992, 96, 9161. https://doi.org/10.1063/1.462226

[7] Bzovska I., Mryglod I.: Condens. Matter. Phys., 2010, 13, 34801. https://doi.org/10.5488/CMP.13.34801

[8] Kostrobij P., Ryzha I.: Math. Model.Comput., 2016, 3, 146. https://doi.org/10.23939/mmc2016.02.146

[9] Gasser R., Smith. E.: Phys. Lett., 1967, 1, 457.

[10] Bertram M., Mikhailov A.: Phys. Rev. E., 2003, 67, 036207. https://doi.org/10.1103/PhysRevE.67.036207

[11] Cisternas Y., Holmes P., Kevrekidis I., Li X.: J. Chem. Phys., 2003, 118, 3312. https://doi.org/10.1063/1.1531070

[12] Connors K.: Chemical Kinetics. The Study of Reaction Rates in Solution. VCH Publishers, New York 1990.

[13] Kostrobiy P., Markovych B., Suchorski Y.: Solid State Phenom., 2007, 128, 219.

https://doi.org/10.4028/www.scientific.net/SSP.128.219

[14] Holst B., Piskur J., Kostrobiy P. et al.: Ultramicroscopy, 2009, 109, 413. https://doi.org/10.1016/j.ultramic.2008.11.021

[15] Suchorski Y.: private communication.

[16] Bzovska I., Mryglod I.: Ukr. Phys. J., 2016, 61, 140. https://doi.org/10.15407/ujpe61.02.0134
[17] Eiswirth M., Krischer K., Ertl G.: Appl. Phys. A., 1990, 51, 79. https://doi.org/10.1007/BF00324269

Received: February 20, 2018 / Revised: March 13, 2018 / Accepted: June 12, 2018

\section{ДВОВИМІРНА МАТЕМАТИЧНА МОДЕЛЬ ПРОЦЕСУ ОКСИДАЦІЇ КАРБОН (II) ОКСИДУ НА ПОВЕРХНІ ПЛАТИНОВОГО КАТАЛІЗАТОРА}

Анотація. Досліджено двовимірну математичну модель оксидачії карбон (II) оксиду (CO) на поверхні платинового каталізатора (Pt) згідно механізму Лангмюра-Гіншелвуда. Враховано впливи структурних змін каталітичної поверхні та температури підложки. Показано, що врахування двовимірностіта структурних змін веде до зміни як динаміки проиесу оксидаиіï, так і області стійкості.

Ключові слова: каталітична реакиія окиснення, реакційно-дифузійна модель, математичне моделювання реакційнодифузійних прочесів. 